\title{
Effects of Spore Availability, Spore Germinability, and Shoot Susceptibility on Gall Rust Infection of Pine
}

\author{
B. D. Moltzan, P. V. Blenis, and Y. Hiratsuka, Department of Agriculture, Food and Nutritional Science and De- \\ partment of Renewable Resources, University of Alberta, Edmonton, Alberta T6G 2P5, Canada, and Northern For- \\ estry Centre, Canadian Forest Service, Natural Resources Canada, 5320-122 Street, Edmonton, Alberta T6H 3S5, \\ Canada
}

\begin{abstract}
Moltzan, B. D., Blenis, P. V., and Hiratsuka, Y. 2001. Effects of spore availability, spore germinability, and shoot susceptibility on gall rust infection of pine. Plant Dis. 85:1193-1199.

Temporal changes in three factors (shoot susceptibility, spore availability, and spore germinability) were evaluated to estimate their effects on the infection of lodgepole pine (Pinus contorta var. latifolia) by Endocronartium harknessii. Germinability of rust spores from sori free of hyperparasites remained above $80 \%$ during the growing season and thus would not have significantly limited infection. In contrast, there was a slight, but statistically insignificant, increase in estimated susceptibility as infection increased from $94 \%$ of maximum at $45 \%$ shoot elongation to maximum susceptibility at $90 \%$ shoot elongation. This was followed by a precipitous decline in estimated susceptibility to $57 \%$ of maximum when shoots were $95 \%$ elongated. Spore availability was $24 \%$ of maximum when shoots were $45 \%$ elongated, and thus may have been limiting at the beginning of the growing season. At the end of the growing season, spore availability declined prior to, or simultaneous with, the decline in susceptibility. The combined effect of both factors drastically reduced the number of infections estimated to occur once shoots are more than $95 \%$ elongated. As shoots elongated, relatively more infections formed higher on the shoot, supporting the hypothesis that periderm is important in limiting infection.
\end{abstract}

Endocronartium harknessii (J.P. Moore) Y. Hiratsuka (Peridermium harknessii J.P. Moore) is an autoecious rust that may cause significant losses in North American hard pine nurseries, Christmas tree plantations, and precommercially thinned stands $(2,3,13)$. Although silvicultural practices may reduce the impact of western gall rust $(3,18)$, there are few practical, direct methods for control. Chemical control has been used on high-value trees $(9,12,20)$, and biological control with hyperparasites such as Scytalidium uredinicola Kuhlman et al. (7) has been suggested. Host resistance may provide long-term control in plantations (1), but the expected benefits of genetic resistance may not be fully realized if the gall rust population is already being regulated by hyperparasites (19).

Regardless of whether chemical or biological control is used, it is essential to know when infection occurs, so that applications of control agents are properly

Corresponding author: P. V. Blenis

E-mail: peter.blenis@ualberta.ca

Part of a thesis submitted by the first author to the Department of Plant Science, University of Alberta, for the degree of Doctor of Philosophy in Forest Pathology.

Accepted for publication 1 August 2001.

Publication no. D-2001-0830-02R

(C) 2001 The American Phytopathological Society timed. Furthermore, when trying to determine if gall rust is regulated by hyperparasites, the focus should be on those that are abundant prior to, or during, the period when pines are commonly infected. Currently, beyond the generalization that infection occurs in the spring and summer when the pathogen is abundant and host tissues are succulent (16), the precise timing of infection is unknown. Similarly, the relative importance of spore availability, spore germinability, and shoot susceptibility in determining the occurrence of infection is uncertain. For example, spore dispersal began as needles of Scots pine (Pinus sylvestris L.) emerged beyond the fascicle sheath and culminated as the needles reached $75 \%$ of their maximum length (12). However, changes in shoot susceptibility were not evaluated, and since the rate of lodgepole pine needle elongation varies with their position on the shoot (B. D. Moltzan, unpublished), it is unlikely that needle elongation could be a reliable estimator of shoot susceptibility in that species. Gall rust spore germinability is affected by temperature, relative humidity (RH), and possibly ultraviolet light (6), but there are no data available to indicate if germinability changes during the growing season. As for susceptibility, seedlings inoculated at two different maturity levels differed in disease incidence (10), but the pattern of shoot susceptibility accompanying the continuous change in shoot development is unknown. Therefore, our goal was to evaluate how spore availability, spore germinability, and shoot susceptibility changed over the growing season. Specifically, we wished to estimate both their relative and combined effects in limiting infection over the growing season.

Although spore availability and spore germinability can be directly measured in the field, changes in susceptibility with shoot development are most easily measured by controlled inoculations performed indoors. To make meaningful comparisons between field and indoor observations, one would need to assume that seedling development is similar under both conditions. Histological examination could support this assumption and would also provide an opportunity to achieve a second objective, determining if changes in shoot development are accompanied by changes in location of galls along the shoot, and if so, whether the location of infections is associated with tissues present at the time of inoculation. It has been stated that infections are more common prior to periderm formation (16). If that is true and if periderm develops acropetally, then galls would be expected to appear at successively higher levels on successively older shoots.

\section{MATERIALS AND METHODS}

Temporal changes in spore production and spore germinability in the field. Studies were conducted in 1992 and 1993 in two Pinus contorta stands located near Hinton, Alberta. Stand 1 was 20 years old and 21 hectares in size, and stand 2 was 19 years old and 86 hectares in size. Spore traps, consisting of glass microscope slides $(25 \times 150 \mathrm{~mm})$ thinly coated with silicon grease, were mounted on top of wooden dowels approximately $1 \mathrm{~m}$ in height. Twenty spore traps were spaced $60 \mathrm{~m}$ apart along one transect per site in 1992. Ten spore traps were used per site in 1993. Two-day totals of spore production were determined from 20 May to 17 July 1992 and from 21 April to 7 July 1993.

To determine spore germinability, 10 galls with no signs of hyperparasitism were collected from both stands at weekly intervals from 20 May to 29 June 1992 and from 10 May to 1 July 1993. Within 30 min of gall collection, spores were dislodged by a short burst of air onto the surface of $1.5 \%$ water agar plates, one plate 
per gall. Germinability was assessed by determining the percent germination of 100 spores following 12-h incubation in darkness at $18^{\circ} \mathrm{C}$.

Greenhouse inoculations. Spores were collected from four locations near Hinton, Alberta, in 1993 and 1994. Spores from 2 to 15 galls were combined to make single spore lots, which were passed through a $45-\mu \mathrm{m}$ sieve, placed in open $30-\mathrm{ml}$ vials, kept up to 5 days at $4{ }^{\circ} \mathrm{C}$ in a desiccator containing $\mathrm{CaCl}_{2}$, transferred to 2-ml vials, and stored in liquid nitrogen. Controlled inoculations were conducted in 1994 and 1995. Dormant 2-year-old $P$. contorta seedlings were obtained from the Pine Ridge Forest Nursery (Smoky Lake, Alberta) and maintained in cold storage at $-4^{\circ} \mathrm{C}$. Four separate inoculations were done in both 1994 and 1995. Prior to each inoculation, a set of seedlings was removed from cold storage each week over a 4-week period so that there would be seedlings of different ages at the time of inoculation. The seedlings were allowed to thaw for 2 days at $4^{\circ} \mathrm{C}$, planted in "Fives" Spencer/Lemaire Rootrainer trays with a mixture of limesupplemented peat ( $\mathrm{pH} 5.5$ ), and maintained in a greenhouse under an 18-h photoperiod at $20^{\circ} \mathrm{C}$. Prior to inoculation, three vials of spores, each from a different spore lot, were removed from liquid nitrogen, warmed in a $40^{\circ} \mathrm{C}$ water bath for $5 \mathrm{~min}$, and combined. Percent germination was determined as above at the time of each inoculation.

A no. 12 paint brush was used to apply spores over the entire elongating terminal shoot. Seedlings were inoculated 3 days after the last of the four sets of trees per inoculation had been removed from storage. Hence, seedlings would have been on the greenhouse bench for $3,10,17$, or 24 days prior to inoculation. Seedlings were arranged in trays so that in 1994 each tray had three seedlings and in 1995 each tray had five seedlings for each of the four different times trees had been in the greenhouse. In each year, there were four separate inoculations, consisting of six inoculated trays and one control tray, for a total of 336 seedlings in 1994, and five inoculated trays and one control tray for a total of 480 seedlings in 1995. Following inoculation, trays were placed in wire mesh incubation cages, covered with moistened paper towels, sealed in separate opaque plastic bags, and incubated for $24 \mathrm{~h}$ at $18^{\circ} \mathrm{C} \mathrm{(4).}$

The lengths of all elongating shoots were measured at the time of inoculation and again after elongation had ceased. Shoot elongation at the time of inoculation was expressed as a percentage of final shoot length. Following incubation, the trees were transplanted into separate $15-\mathrm{cm}$ pots and maintained in the greenhouse. The frequency and location of galls was recorded after 5 months.

Analysis and comparison of field and greenhouse results. The field data showed the availability and germinability of spores in relation to date. In contrast, for each tree in the greenhouse trial, susceptibility (tree infected or uninfected) was known in relation to percent elongation at the time of inoculation. Several steps were required to combine these data and estimate the relative importance of spore availability, spore germinability, and shoot susceptibility as constraints to infection at different stages of shoot development. First, in the field, lengths of the current year's shoots were measured each week on eight trees per site on the same days that spore availability and germinability were assessed. Five shoots per tree, distributed approximately uniformly over the easily accessible portion of the crown, were measured. Percent shoot elongation at each date was defined as the shoot length at that date expressed as a percentage of final shoot length. Secondly, a second-order polynomial was used to express percent shoot elongation as a function of date. Separate functions were developed for each site and year. Finally, these relationships between date and shoot elongation were applied to the data on date, spore availability, and spore germinability so that spore availability and germinability could be plotted against percent shoot elongation.

Data from all replicates of the greenhouse inoculations over both years were pooled. Based on percent shoot elongation at the time of inoculation, 20 classes of percent shoot elongation, with an equal number of trees in each class, were established. Elongation classes ranged from 0 to $26 \%$ elongation to $100 \%$ elongation. Relative susceptibility to infection in each class was defined as the number of galls in that class expressed as a percentage of the total number of galls. Piece-wise regression (11) was used to model the relationship between relative susceptibility and percent shoot elongation at the time of inoculation. This procedure used least squares estimation to estimate the point of maximum susceptibility and calculated separate linear regressions on either side of this point. It was chosen because we expected infection to initially increase as a consequence of increased target size and then decrease once the elongating shoot became less succulent.

The plots of spore production and spore germinability versus percent shoot elongation were superimposed on the plot of relative susceptibility versus percent shoot elongation and examined to estimate the factor(s) most important in limiting infection.

Validation of the use of greenhousegrown trees. The foregoing procedures for determining the relative importance of spore availability, spore germinability, and shoot susceptibility in limiting infection in the field rested on the assumption that the relationship between shoot development and susceptibility would be the same under both greenhouse and field conditions. To determine if that assumption was reasonable, histological comparisons were made between field- and greenhouse-collected shoots to determine if the two types of material had similar internal tissue development at similar stages of elongation.

Immediately after incubation, all seedlings inoculated on a particular date as part of the greenhouse study were subdivided into sets of three trees, called triplets. The elongating shoots within a triplet were similar in length and appearance. From one randomly selected tree per triplet, the expanding terminal shoot was excised for histological examination and fixed in formalin-acetic-acid (FAA), while the remaining two trees were returned to the greenhouse for gall development. As noted above, percent shoot elongation at the time of inoculation was expressed as a percentage of final shoot elongation. Because final shoot elongation could not be determined for the trees sacrificed for histology, their percent shoot elongation at the time of inoculation was assumed to equal that of the other two trees in the triplet.

In 1992 and 1993, at both field sites, shoots were excised at weekly intervals over the growing season and fixed in FAA. They were taken from the same trees that were being repeatedly measured in order to determine the relationship between date and shoot elongation. Shoot elongation of the field-collected shoots at the time of removal was assumed to be equal to the average shoot elongation of the repeatedly measured shoots at that time.

From the top, middle, and bottom of the FAA-preserved shoots, $3 \times 3 \times 3 \mathrm{~mm}$ blocks were cut, dehydrated, embedded in paraffin, and sectioned on a rotary microtome. Sections were mounted, stained in Safranin-Fast Green (8), and examined under bright-field and phase-contrast illumination.

Gall location. As greenhouse trees were evaluated for infection, the length of the shoot and the location of any galls were recorded. Simple linear regression was used to determine if there was a relationship between gall location (defined as distance from the base of the shoot as a percentage of total shoot length) and shoot elongation at the time of inoculation.

\section{RESULTS}

Temporal changes in spore production and spore germinability in the field. In 1992, spore production at site 1 was maximum (Fig. 1A) when sampling began on 1 June, by which time shoots were 62 to $70 \%$ elongated (Fig. 1E). At site 2, maximum sporulation occurred in the second week of June when shoots were 82 to $88 \%$ elongated. At both sites, spore capture declined as shoots elongated from 85 to $100 \%$ of their final lengths, and by midJuly few spores were caught. Similarly, in 1993, sporulation gradually increased dur- 
ing the second, third, and fourth weeks of May (Fig. 1B) as shoots elongated to 45 to $60 \%$ of their final lengths. Peak sporulation occurred during the second week of June, when shoots reached 75 to $80 \%$ of their final lengths. Spore capture declined after mid-June and fell to minimal levels by the beginning of July (Fig. 1B). During this time, shoots elongated from 80 to $100 \%$ of their final lengths (Fig. 1F).
Once sufficient spores could be gathered from galls, assessment of spore germinability began and continued weekly from 20 May to 29 June 1992 and from 10 May to 1 July 1993. Spore germinability remained above $80 \%$ at both sites in 1992 as shoots elongated from 70 to $100 \%$ of their final lengths (Fig. 1C). Spore germinability remained above 91\% at both sites in 1993 as shoot elongation increased from 55 to $100 \%$ (Fig. 1D).
Greenhouse inoculations. Germinability of combined spore lots used for the inoculations exceeded $80 \%$. On average, $31 \%$ of the inoculated trees developed galls. Seedlings inoculated 3,10, 17, and 24 days post-storage had average infection frequencies of $32,41,36$, and $12 \%$, respectively. Whereas 26 and $27 \%$ of the trees inoculated 3 or 10 days post-storage had multiple galls, respectively, multiple galls
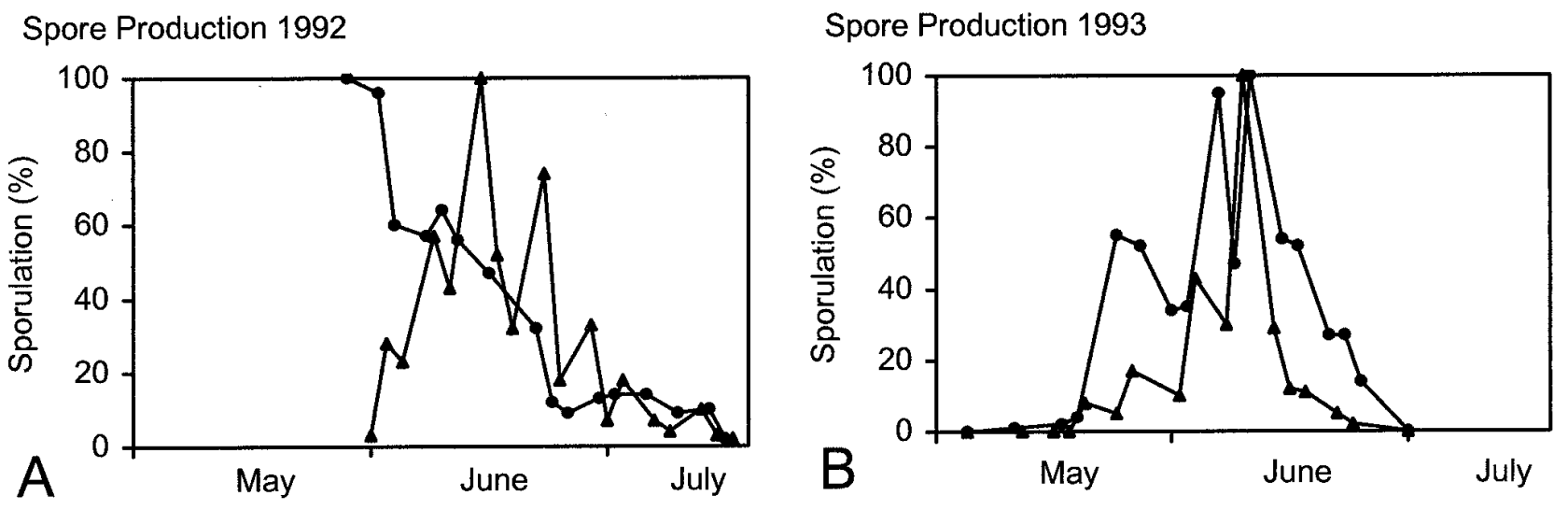

Spore Germination 1992

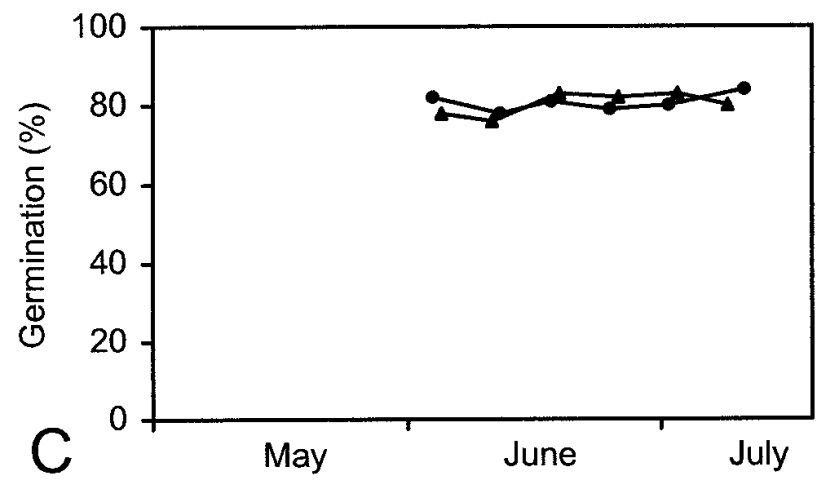

\section{Shoot Elongation 1992}

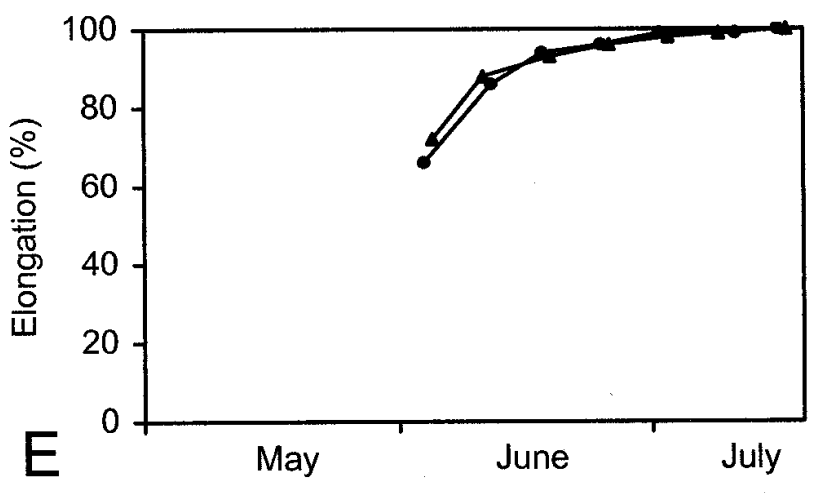

\section{Spore Germination 1993}

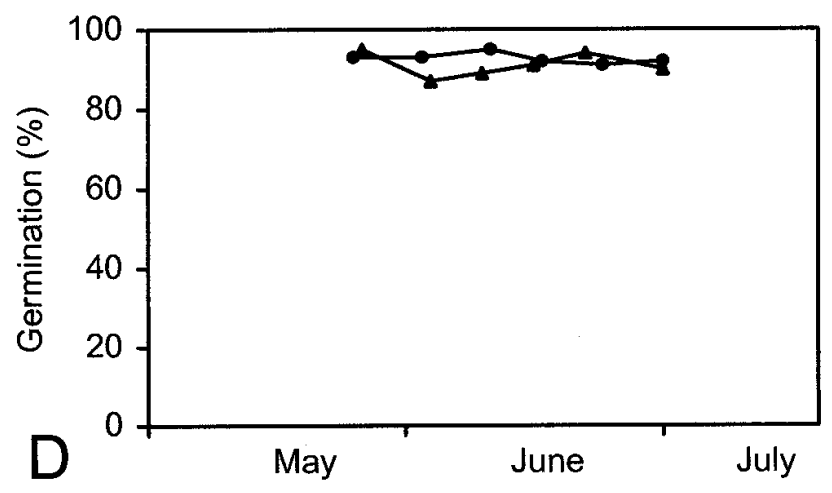

\section{Shoot Elongation 1993}

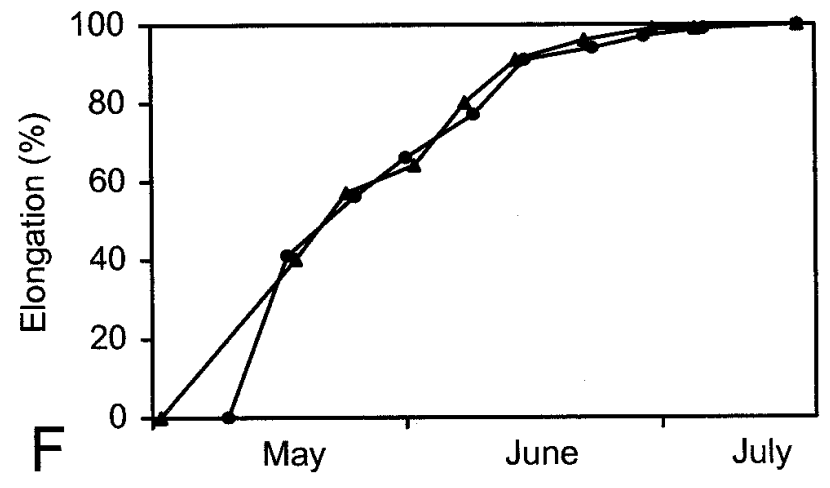

- Site 1

$\triangle$ Site 2

Fig. 1. Summary of field data. Spore production for site 1 and site 2 in 1992, A; and 1993, B. Values are expressed as a percentage of the maximum production for each site and year. Spore germination for both sites in 1992, C; and 1993, D. Values are the actual percent germination. Shoot elongation for both sites in 1992, E; and 1993, F. Values are expressed as a percentage of the maximum elongation for each site and year. 
were present on only 15 and $2 \%$ of the trees inoculated 17 and 24 days poststorage, respectively. In the latter case, the single galls were typically located near the distal end of the shoot.
Analysis and comparison of field and greenhouse results. In both stands, and in both years, shoot elongation reached 90,95 , and $100 \%$ of final length by the third and fourth weeks of June and the

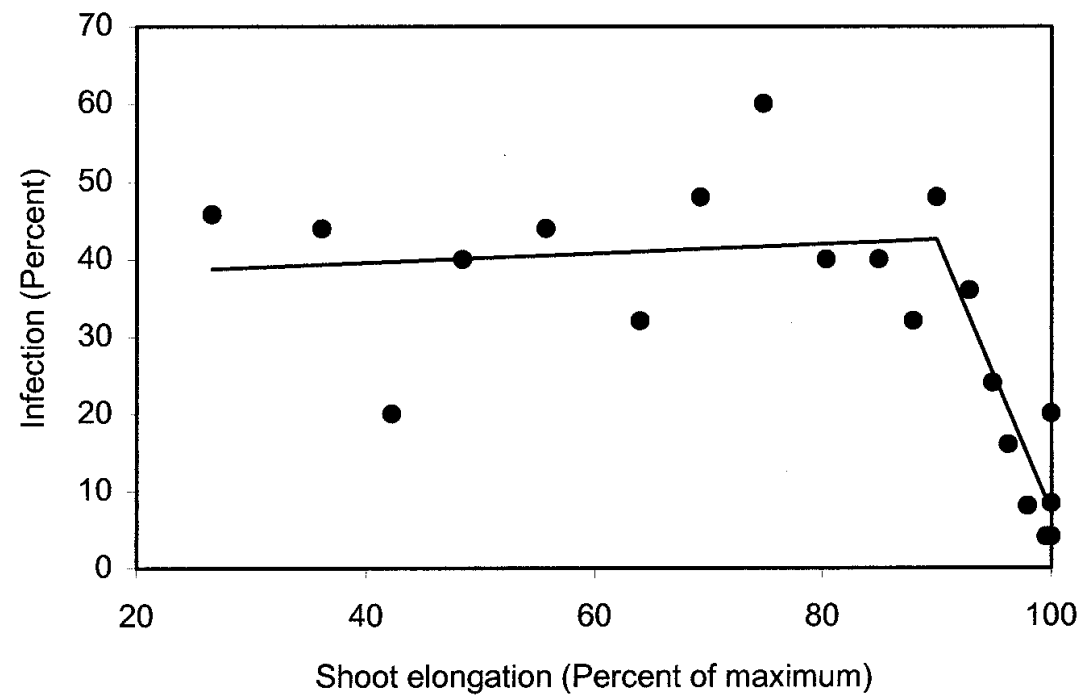

Fig. 2. Susceptibility to infection as a function of shoot elongation. Percent infection was plotted against average shoot elongation for 20 shoot elongation classes with 24 to 25 trees in each. The trend line represents estimated infection derived from piece-wise regression (11).

first week of July, respectively (Fig. 1E and F). For each combination of year and stand, percent shoot elongation could be accurately estimated based on date; coefficients of determination for the secondorder polynomials fitted through the plots of percent elongation and date had $R^{2}$ values of 0.95 to 0.99 depending on year and site.

The estimated relationship between shoot elongation and infection frequency obtained from the piece-wise regression was:

(1) $Y=37.2+0.059\left(X_{1}\right)-3.50\left(X_{2}\right) ; K=90$

where:

$Y=$ estimated percent infection

$K=$ shoot elongation at which estimated infection was maximum

$X_{1}=$ shoot elongation

$X_{2}=($ shoot elongation $-K)$ if shoot elongation $>K, 0$ otherwise

Shoot elongation $=$ shoot length as a percentage of final length

Maximum estimated susceptibility occurred when the shoots were $90 \%$ (95\% confidence interval $=85$ to $95 \%$ ) elongated (Fig. 2). Although the estimated disease incidence gradually increased (slope = 0.059 ) to a maximum, this slope was not significantly different from $0(P=0.34)$. In
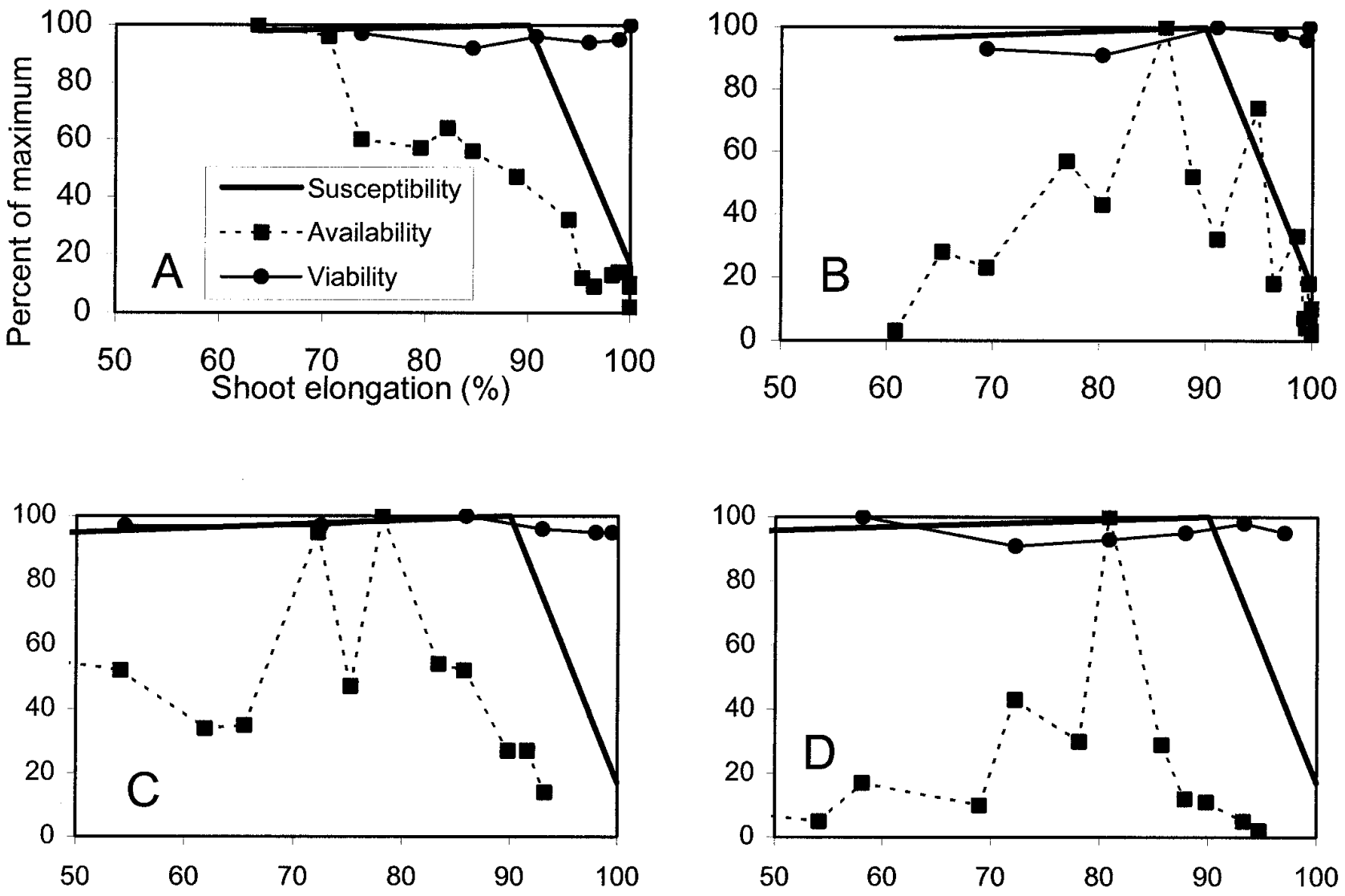

Fig. 3. Changes in shoot susceptibility, spore availability, and spore germinability as a function of shoot elongation. Susceptibility values were estimated by piece-wise regression of infection against shoot elongation under greenhouse conditions and thus are the same in all four charts. Spore availability and spore germinability were determined under field conditions in site 1 in 1992, A; site 2 in 1992, B; site 1 in 1993 , C; and site 2 in 1993 , D. All values are expressed as a percentage of the maximum estimated values (susceptibility) or maximum observed values (spore availability and germinability). 
contrast, the subsequent decline in infection frequency was significant $(P<0.001)$.

Overlay plots of spore production, spore germinability, and susceptibility data indicated that spore germinability remained relatively constant over the growing season (Fig. 3). In contrast, spore production lagged behind estimated relative susceptibility at the beginning of the growing season. At the end of the growing season, there was a marked decline in spore production that either preceded (site 1, 1992; sites 1 and 2,1993) or was approximately concurrent with (site 2, 1992) the decline in susceptibility (Fig. 3).

Validation of the use of greenhousegrown trees. There was little variation in final shoot length between the two trees per triplet for trees assigned to triplets 17 or 24 days post-storage (coefficients of variation were 6.1 and $6.8 \%$, respectively). In contrast, there was greater variation in final shoot lengths between trees that had been grouped into triplets 3 or 10 days post-storage (coefficients of variation were 21.5 and $8.0 \%$, respectively).

Tissue differentiation increased from the bottom to the top of expanding shoots in both greenhouse-grown and field-collected samples. For example, there was no periderm in samples taken from the tops of shoots that were $80 \%$ elongated, whereas the bottom of the shoots had phellogen, phelloderm, and several layers of phellem. Therefore, histological comparisons between greenhouse and field samples were made from the middle of the shoots.

Patterns of vascular cambium and periderm differentiation in the middle of elongating shoots were similar for greenhouse-grown and field-grown trees at the same stage of development (Fig. 4). Shoots that were 30 to $40 \%$ elongated had vascular bundles and procambium, but no vascular cambium or periderm. At $80 \%$ elongation, there was an increase in secondary xylem in the vascular bundles and in most cases a conspicuous vascular cambium. Phellem, phellogen, and phelloderm were apparent. At $90 \%$ elongation, the vascular cambium was well established, the cuticle and epidermis were suberized, and the phellogen and phelloderm were conspicuous.

Gall location. Gall location was linearly related to the degree of stem elongation at the time of inoculation (Fig. 5). For example, on average, galls were formed 18,38 , and $70 \%$ of the way up the current year's shoot on seedlings that were $20 \%, 50 \%$, and fully elongated, respectively, at the time of inoculation.

\section{DISCUSSION}

Many phytopathological investigations have examined temporal changes in spore concentration, spore germinability, and host susceptibility, but typically these three factors have been examined in isolation. The goal of this project was to evaluate all three factors to estimate both their relative importance and their combined effects. Spore germinability was consistently high throughout the growing season at both sites and in both years. Thus, spore germinability would appear to be a negligible constraint to infection. It is important to note, however, that spores were deliberately sampled from galls that appeared to be free of hyperparasites. There are several species of fungi that parasitize E. harknessii galls $(5,17)$, and at least one of these, $S$. uredinicola, is likely playing a significant role in the epidemiology of $E$. harknessii. This hyperparasite was present on $39 \%$ of the galls from 18 stands in Alberta (15) and reduced spore germination from $90 \%$ to $5.5 \%$ (14). Thus, although spore germinability will not likely be limiting where hyperparasitism is uncommon, hyperparasites such as $S$. uredinicola may reduce spore germinability, and thereby infection, in stands where it is prevalent.

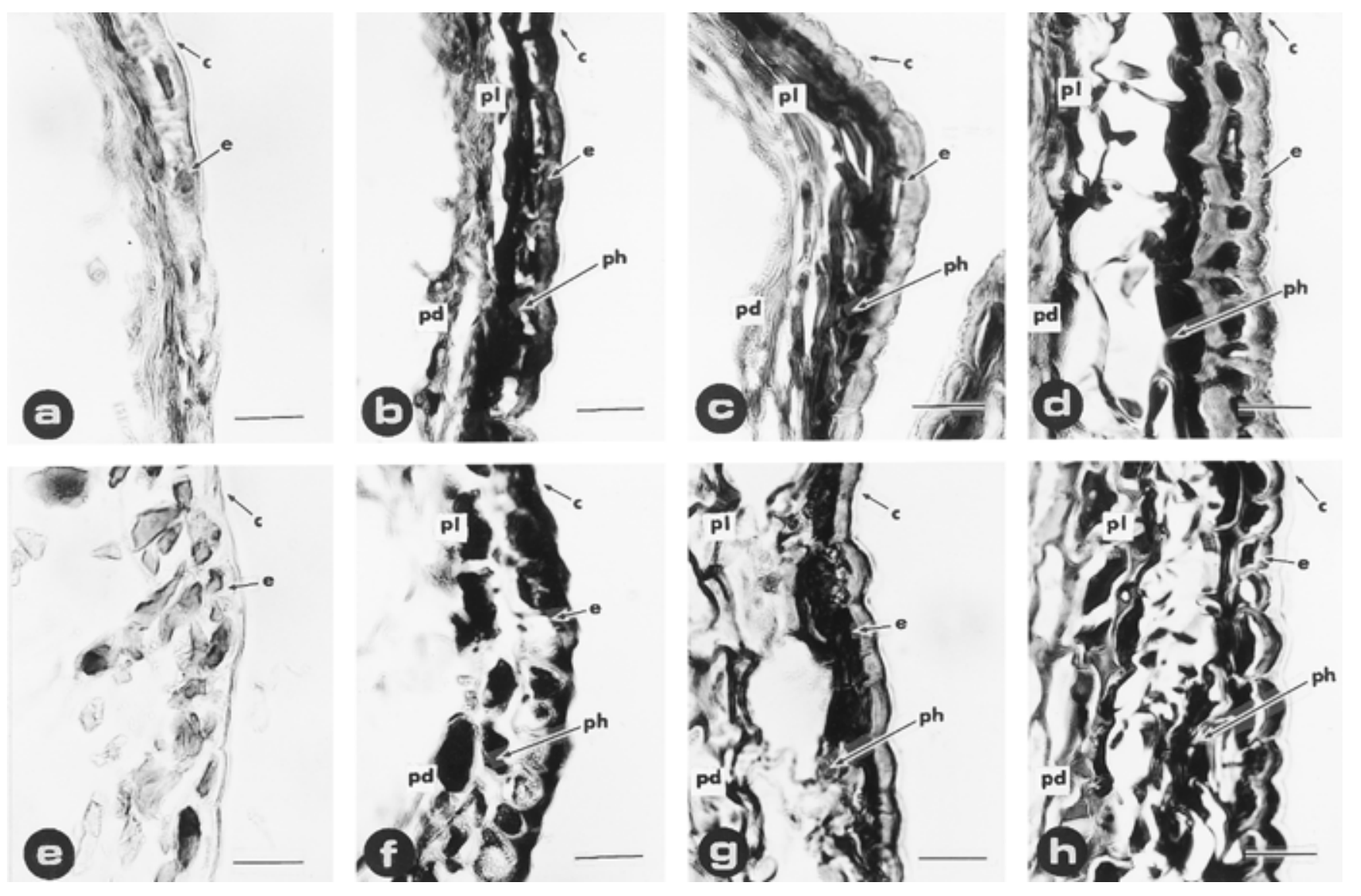

Fig. 4. Periderm differentiation midway along expanding field-collected and greenhouse-grown shoots at similar stages of elongation $(\mathrm{c}=\mathrm{cuticle}$, e $=$ epidermis, $\mathrm{ph}=$ phellem, $\mathrm{pl}=$ phellogen, $\mathrm{pd}=$ phelloderm). Shoots $30 \%$ elongated from field, A; and greenhouse, E. Shoots $80 \%$ elongated from field, $\mathbf{B}$; and greenhouse, F, showing the epidermis, and initial periderm including phellem, phellogen, and phelloderm. Shoots $90 \%$ elongated from field, C; and greenhouse, G, showing epidermis and fully developed periderm including phellem, phellogen, and phelloderm. Shoots fully elongated from field, D; and greenhouse, $\mathbf{H}$, showing cuticle, epidermis, and a thick layer of periderm consisting of phellem, phellogen, and phelloderm. Bar $=25 \mu \mathrm{m}$. 
Comparison of temporal changes in rust spore availability and shoot susceptibility over the growing season was hampered by the great day-to-day variation in spore counts (Fig. 1). By averaging the spore availability data over both stands and years and further smoothing the data by taking 9observation moving averages, two features become apparent if the spore availability and shoot susceptibility data are overlain (Fig. 6). First, spore availability lags behind shoot susceptibility at the beginning of the growing season. E. harknessii is an autoecious rust that produces, on pine, spores capable of infecting other pines.
The pathogen should have been able to evolve to respond to temporal changes in host physiology by producing spores coincident with the period of maximum host susceptibility. It is possible, however, that there may be some advantage in delaying spore release until later in the season when temperatures might be warmer and more favorable for infection. Secondly, after shoots have reached $90 \%$ elongation, both spore availability and shoot susceptibility undergo a sharp decrease, such that the estimated combined effect would be an even sharper decline in the probability of infection. For example, at $90 \%$ of final

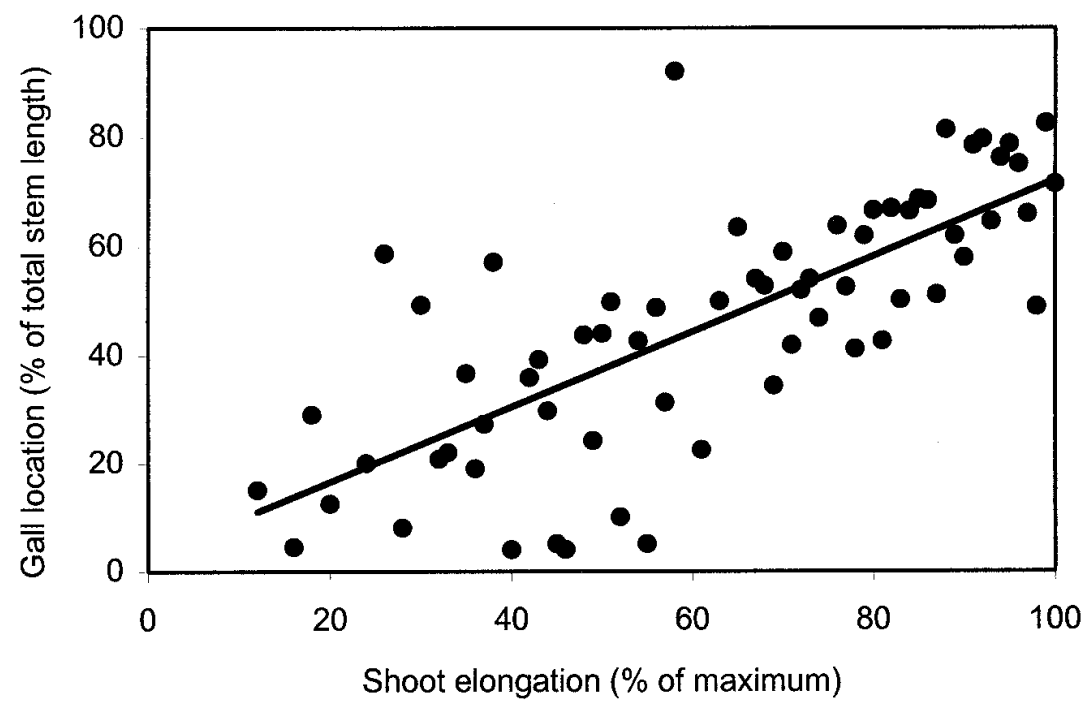

Fig. 5. Regression of gall location versus shoot elongation. Shoot elongation was defined as shoot length at inoculation as a percentage of final shoot length. Gall location values of 0 and $100 \%$ represent the bottom and top of the shoots, respectively. Each point represents the average location of all galls on shoots with a given degree of elongation. The estimated standard deviation around each point was $22 \%$.
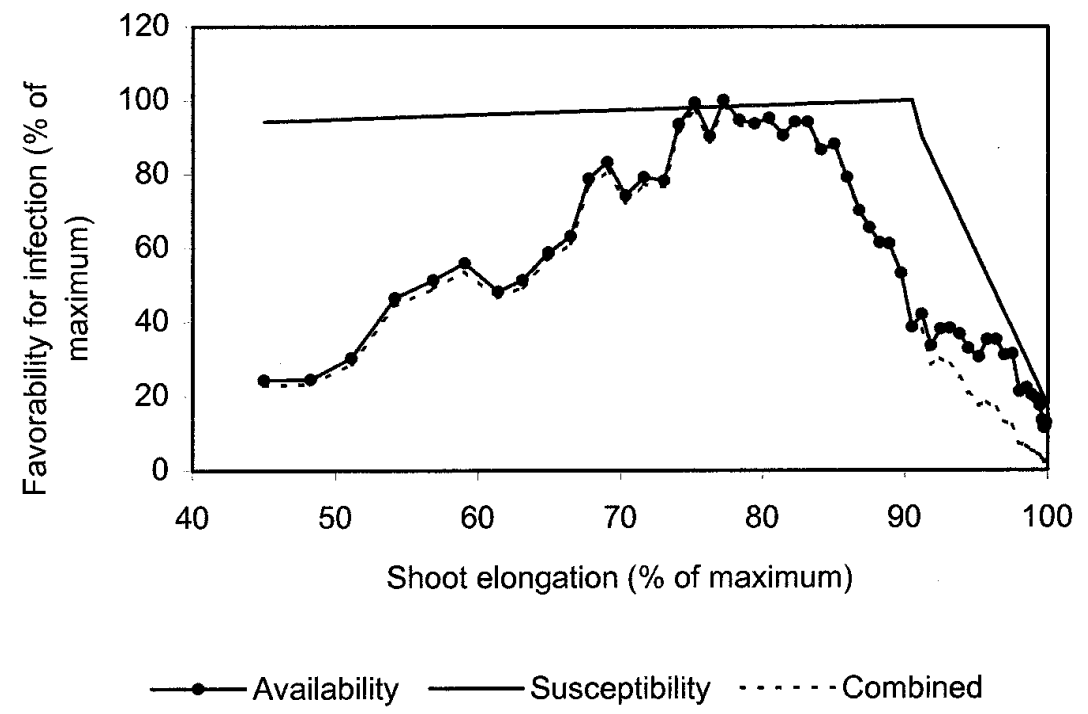

Susceptibility $\cdots \cdot$...-Combined

Fig. 6. Separate and estimated combined effects of shoot susceptibility and spore availability on infection. The trendline for shoot susceptibility represents estimated infection, as a percent of maximum, derived from piece-wise regression (11). The plot of spore availability represents the 9observation moving average over all locations and years, expressed as a percentage of maximum. The combined plot represents the product of shoot susceptibility and spore availability.

shoot elongation, shoot susceptibility and spore availability were 100 and $53 \%$ of maximum, respectively. Under the assumption that the combined effect of both constraints would be the product of the separate constraints, the estimated level of infection would be $53 \%$ of maximum. In contrast, at $98 \%$ elongation, spore availability and susceptibility were 21 and $34 \%$ of maximum, respectively, and thus their estimated combined effect would be to reduce infection to $7 \%$ of maximum.

The practical implication of these results is that since multiple, well-timed applications seem necessary for chemical control of gall rust (20), fungicides will be most effective if treatment occurs after spore release and prior to shoots reaching $90 \%$ of their final development. Moreover, only hyperparasites operating prior to shoots growing to $90 \%$ are likely to directly reduce rust infection. $S$. uredinicola has been shown to be active as early as April in west-central Alberta (14) and as such may have a significant effect on the epidemiology of E. harknessii. In contrast, the hyperparasite Cladosporium gallicola Sutton was rarely found prior to mid-June and at one site was first found on 30 June (14). Thus it likely is far less effective in reducing the spread of western gall rust.

Estimation of temporal changes in shoot susceptibility in the field rested on the assumption that the relationship between susceptibility and shoot elongation would be similar under field and greenhouse conditions. This assumption seems justified based on the histological studies, which showed similar anatomical features for greenhouse-grown and field-grown trees at the same stage of shoot elongation.

Histological examination was necessary to validate the experimental approach, but also provided an opportunity to test the hypothesis that spatio-temporal changes in anatomy would be accompanied by changes in the location of infection. There was quite a strong relationship between the degree of shoot elongation and gall location (Fig. 5), with lower shoot infections becoming far less frequent on older shoots. Since periderm formation proceeded acropetally, it is quite possible that periderm was important in limiting infections at the base of those older shoots. However, periderm formation would not likely have been responsible for the paucity of infections near the tops of younger shoots (Fig. 5). Because elongation initially occurred more rapidly at the base of the elongating shoot than at the top, the distal portion of the shoot would have been covered with bud scales at the early stages of elongation and thus protected from infection. Thus, the linear correlation between degree of shoot elongation and the location of infection may be the result of two different processes, bud scales and lack of elongation limiting infection at the 
top of young shoots and periderm limiting infection at the bottom of older shoots.

In summary, greenhouse and laboratory studies showed that, in the absence of hyperparasites, spore germinability would not be a major constraint to infection of lodgepole pine by E. harknessii. In contrast, spore availability would likely limit infection at the beginning of the growing season, and the combined effects of declining spore availability and declining shoot susceptibility would be expected to greatly limit infection once shoots were more than $90 \%$ elongated. This more precise definition of the infection period should be helpful to those considering chemical or biological control of western gall rust or the epidemiology of hyperparasites that may be regulating the gall rust pathosystem. There was a correlation between degree of shoot elongation and the location of infections, perhaps because of different processes limiting infections at the tops and bottoms of younger and older shoots, respectively.

\section{ACKNOWLEDGMENTS}

The assistance of Ian Duncan, Pak Chow, Shirley Brezden, Gordon Latham, Brett McConkey, Max Amerongen, and Mitch deBeus is gratefully acknowledged, as are the critical comments provided by Patricia E. Crane and P. Chakravarty of the Canadian Forest Service, Edmonton, Alberta. This project was funded by the Natural Sciences and Engineering Research Council of Canada.

\section{LITERATURE CITED}

1. Allen, E. A., Blenis, P. V., and Hiratsuka, Y. 1990. Early symptom development in lodgepole pine seedlings infected with E. harknessii. Can. J. Bot. 68:270-277.

2. Bella, I. E., and Navratil, S. 1988. Western gall rust dynamics and impact in young lodgepole pine stands in west-central Alberta. Can. J. For. Res. 18:1437-1442.

3. Blenis, P. V., and Duncan, I. 1997. Management implications of western gall rust in precommercially thinned lodgepole pine stands. Can. J. For. Res. 27:603-608.

4. Blenis, P. V., and Pinnell, H. D. 1991. Inoculating lodgepole pine with E. harknessii. Pages 297-301 in: Rusts of Pine. Proc. 3rd IUFRO Rusts Pine Working Party Conf. Y. Hiratsuka, J. K. Samoil, P. V. Blenis, P. E. Crane, and B. L. Laishley, eds. For. Can., Northwest Reg., North. For. Cent., Edmonton, Alberta. Inf. Rep. NOR-X-317.

5. Byler, J. W., Cobb, F. W., Jr., and Parmeter, J. R., Jr. 1972. Occurrence and significance of fungi inhabiting galls caused by Peridermium harknessii. Can. J. Bot. 50:1275-1282.

6. Chang, K.-F., Blenis, P. V., and Hiratsuka, Y. 1989. Survival of Endocronartium harknessii teliospores in a simulated airborne state. Can. J. Bot. 67:928-932.

7. Currie, C. R., and Hiratsuka, Y. 1996. Evaluating insect-mediated dispersal of Scytalidium uredinicola for biological control of western gall rust. Can. J. For. Res. 26:1754-1760.

8. Jensen, W. A. 1962. Botanical Histochemistry: Principles and Practice. W. H. Freeman, London.

9. Kistler, B. R., and Merrill, W. 1978. Seasonal development and control of pine-pine gall rust (Endocronartium harknessii). Am. Christmas Tree J. 22:21-23.

10. Kojwang, H. O., and van der Kamp, B. J. 1992. Early symptoms and resistance of lodgepole pine seedlings inoculated with western gall rust. Can. J. Bot. 70:1274-1278.

11. Littell, R. C., Freund, R. J., and Spector, P. C. 1991. SAS System for Linear Models. 3rd ed. SAS Institute, Cary, NC.

12. Merrill, W., and Kistler, B. R. 1976. Phenology and control of Endocronartium harknessii in Pennsylvania. Phytopathology 66:12461248.

13. Merrill, W., and Wenner, N. G. 1988. Facts on pine gall rust. N.Y. Christmas Tree Grower's Assoc. Bull. 23:6-7.

14. Moltzan, B. D. 1998. Factors influencing western gall rust infection on lodgepole pine and the seasonal development of the mycoparasite Scytalidium uredinicola. Ph.D. thesis. Department of Plant Science, University of Alberta, Edmonton.

15. Moltzan, B. D., and Blenis, P. V. 1999. Effects of gall age, gall size, and rust severity on incidence of the mycoparasite Scytalidium uredinicola. Can. J. For. Res. 29:1604-1609.

16. True, R. 1938. Gall development on Pinus sylvestris attacked by the Woodgate Peridermium and morphology of the parasite. Phytopathology 28:24-50.

17. Tsuneda, A., Hiratsuka, Y., and Maruyama, P. J. 1980. Hyperparasitism of Scytalidium uredinicola on western gall rust Endocronartium harknessii. Can. J. Bot. 58:1154-1159.

18. van der Kamp, B. J. 1994. Lodgepole pine stem diseases and management of stand density in the British Columbia interior. For. Chron. 70:773-779.

19. van der Kamp, B. J., and Blenis, P. V. 1996. A model of hyperparasite regulation of the gall rust-lodgepole pine pathosystem. Can. J. For. Res. 26:1256-1265.

20. Wenner, N. G., and Merrill, W. 1988. Evaluation of benefit to control pine-pine gall rust on Scots pine Christmas trees, 1986-87. Fungic. Nematicide Tests 43:287. 